\title{
Characterization and Magnetic Properties of Zinc Ferrite Synthesized by Combustion Route
}

\author{
Anil S. Jadhav¹, B. Raghunanda², Ashok D. Shetkar ${ }^{3}$, Ajai Kumar S. Molakeri ${ }^{*}$ \\ ${ }^{1}$ Department of Mechanical Engineering, Guru Nanak Dev Engineering College, Bidar - 585 403, Karnataka, India. \\ ${ }^{2}$ Department of Physics, Government First Grade College, Bidar - 585 401, Karnataka, India. \\ ${ }^{3}$ Department of Physics, Karnataka Arts, Science and Commerce College, Bidar - 585 401, Karnataka, India. \\ ${ }^{4}$ Department of Physics, Guru Nanak Dev Engineering College, Bidar - 585 403. Karnataka, India.
}

\section{ARTICLE DETAILS}

Article history:

Received 02 October 2018

Accepted 18 October 2018

Available online 11 November 2018

Keywords:

Zinc Ferrite

Nanoparticles

Magnetic Saturation

\begin{abstract}
A B S T R A C T
Zinc ferrite $\left(\mathrm{ZnFe}_{2} \mathrm{O}_{4}\right)$ nanocrystalline powder material was prepared by combustion method. The X-ray diffraction (XRD) and scanning electron microscopy (SEM) is used to study on structural properties. The magnetic properties of the sample were measured at room temperature using vibrating sample magnetometer (VSM) in the field range $\pm 15000 \mathrm{G}$. Hysteresis loop obtained room temperature for $\mathrm{ZnFe}_{2} \mathrm{O}_{4}$ nanoparticles indicates that the nanoparticles are ferromagnetic in nature.
\end{abstract}

\section{Introduction}

The special features of nanomaterials arising because of their unique physical properties viz., electrical conductivity, optical band gap, refractive index, magnetic properties and superior mechanical properties such as hardness of nanomaterials are being gradually revealed and understood by many researchers. A new field of study known as "nanotechnology" has been emerged due to deep understanding of these unique behaviors and applications of nanostructured materials by the research community $[1,2]$. Among various nanomaterials, magnetic nanoparticles mainly spinel ferrite $\left(\mathrm{MFe}_{2} \mathrm{O}_{4}, \mathrm{M}=\mathrm{Ni}, \mathrm{Co}, \mathrm{Mn}, \mathrm{Zn}\right.$ etc.) nanoparticles, are of special interest for their attractive scientific and technological aspects in different fields such as magnetic recording and separation, catalyst, photocatalyst, drug delivery, pigments, ferrofluids, magnetic resonance imaging (MRI), hot gas desulfurization etc., [3-8]. Apart from these applications spinel ferrites can also be used in many electronic devices due to their high permeability at high frequencies, high mechanical hardness, chemical stability and reasonably low cost. The spinel ferrites are highly suitable for computer memories, logical devices, transformer cores, recording heads etc. The size of the grain plays an important role in all these applications [9]. The synthesis of spinel ferrites is being carried out by different techniques in order to achieve desired size and shape and to improve their physical properties and widen the scope of their applications $[10,11]$. Different methods, such as traditional ceramic synthesis [12], ion implantation [13], co-precipitation [14], ball milling [15], sol-gel combustion [16] combustion method [17] etc. have been adopted by the scientists to prepare zinc ferrite nanoparticles. Here, we have successfully synthesized zinc ferrite nanoparticles by combustion route.

\section{Experimental Methods}

\subsection{Materials and Methods}

All the chemicals were of AR grade and were used as received. Doubledistilled water was used for preparation of the required solutions.

\subsection{Synthesis of Zinc Ferrite $\left(\mathrm{ZnFe}_{2} \mathrm{O}_{4}\right)$ Nanoparticles by Combustion Route}

Zinc ferrite $\left(\mathrm{ZnFe}_{2} \mathrm{O}_{4}\right)$ nanoparticles were prepared by known quantity of zinc salt and iron salt was mixed thoroughly and is grounded well with polyvinyl alcohol in 1:5 in a pestle and mortar. The reaction mass was transferred in to crucible initially burnt in an electrical oven for complete evolution of the fumes. The resultant residue was heated continuously for complete combustion. The reaction was completed within 30 minutes to form brown colored crystalline $\mathrm{ZnFe}_{2} \mathrm{O}_{4}$ is formed. On cooling to room temperature carbon contaminations in the ferrite sample is removed by treating with acetone. The carbon flowts on the acetone is decanted and evaporated the acetone [18-21]. The various steps involved in the synthesis of $\mathrm{ZnFe}_{2} \mathrm{O}_{4}$ nanoparticles are shown in flow chart (Fig. 1).

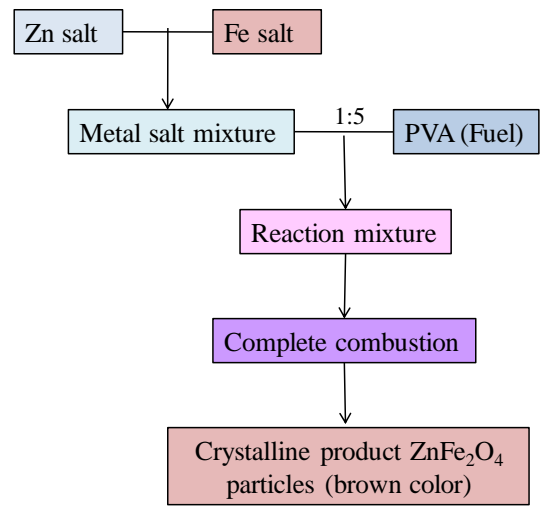

Fig. 1 Flow chart: Synthesis of $\mathrm{ZnFe}_{2} \mathrm{O}_{4}$ nanoparticles

\subsection{Characterization Techniques}

The X-ray diffraction patterns of the samples in this present study are obtained on Bruker AXS D8 Advance, X-ray diffractometer using $\mathrm{CuK}_{\alpha}$ radiation $(\lambda=1.5406 \AA)$. The diffractograms were recorded in terms of $2 \theta$ in the range $20^{\circ}-120^{\circ}$ with a scanning rate of $2^{\circ}$ per minute. The Joel model JSM-6390 LV scanning electron microscope (SEM) is used to observe the morphology and particle size distribution of the samples. The magnetization measurements of the samples were carried out using measured using vibrating sample magnetometer (LakeShore, Model7410 ) at room temperature with a maximum field of $-15000 \mathrm{G}$ to +15000 G. 


\section{Results and Discussion}

\subsection{XRD Analysis}

Fig. 2 displays the $\mathrm{X}$ - Ray diffraction pattern of $\mathrm{ZnFe}_{2} \mathrm{O}_{4}$ and it is observed that the peaks consummately coordinate with the polycrystalline nature type of zinc ferrite JCPDS No. 82-1042. The prominent peaks corresponds to $2 \theta=29.87^{\circ}, 35.32^{\circ}, 40.58^{\circ}, 42.98^{\circ}$, $49.21^{\circ}, 53.80^{\circ}, 57.09^{\circ}, 62.23^{\circ}, 63.75^{\circ}$ and $71.66^{\circ}$ are due to (220), (311), (222), (400), (331), (422), (511), (440), (531) and (620) planes of $\mathrm{ZnFe}_{2} \mathrm{O}_{4}$ respectively. The crystalline size was determined by Scherrer's formula [22]. The sizes of the $\mathrm{ZnFe}_{2} \mathrm{O}_{4}$ nanoparticles were estimated over the range 24 to $30 \mathrm{~nm}$. The particle size calculated differ from peak to another peak, which may be due to strain effect on the line width [23].

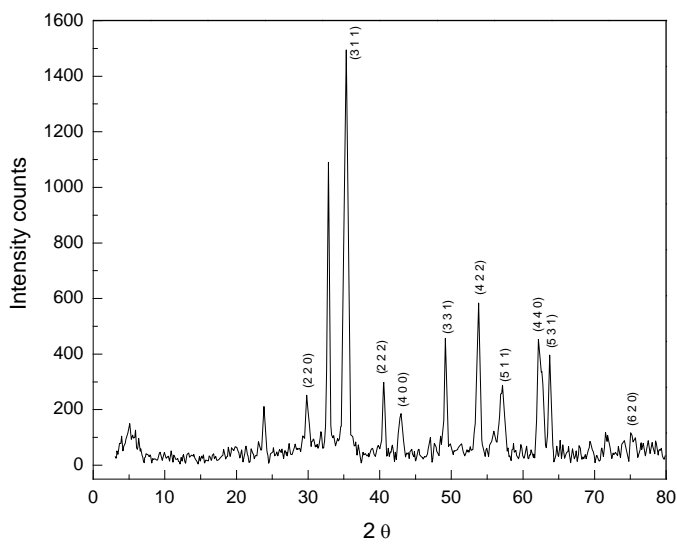

Fig. $2 \mathrm{X}$-Ray diffraction patterns of $\mathrm{ZnFe}_{2} \mathrm{O}_{4}$ nanoparticles

\subsection{SEM Analysis}

The morphological characteristics of the obtained $\mathrm{ZnFe}_{2} \mathrm{O}_{4}$ were investigated by SEM analysis to visualize the size and shape and to confirm the nanocrystalline nature. Fig. 3 shows the SEM image of as synthesized zinc ferrite nanoparticles and it is clearly shows that they are agglomerated, highly branched and porous in nature.

SEM images of zinc ferrite nanoparticles were not well resolved, because samples are highly magnetic and intensity of electron beam of SEM may not be sufficient to provide the required resolution to make estimates of sample sizes. Thus the particles are not well resolved and magnified. This fact makes it impossible to make accurate estimates of particle size distribution of SEM image of samples. Particle size distribution was determined by using image J software to obtain the maximum size distribution range by selected area of the SEM image of the zinc ferrite nanoparticles was found to be $26-129 \mathrm{~nm}$. SEM Micrographs with the particle size pie graph (Fig. 4) showing with maximum size distribution range of $\mathrm{ZnFe}_{2} \mathrm{O}_{4}$ nanoparticles are given below.

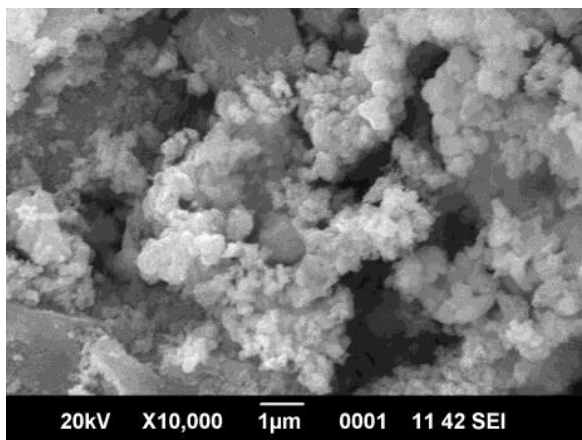

Fig. 3 SEM image of $\mathrm{ZnFe}_{2} \mathrm{O}_{4}$ nanoparticles

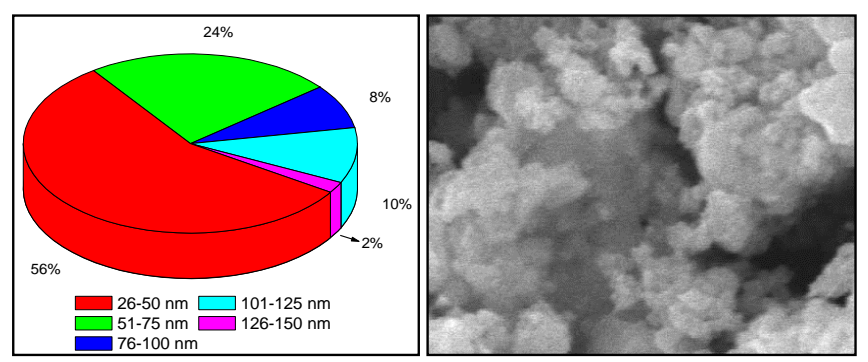

Fig. 4 SEM micrograph with the particle size pie graph of $\mathrm{ZnFe}_{2} \mathrm{O}_{4}$ nanoparticles

\subsection{Magnetic Properties}

Fig. 5 shows a typical hysteresis loop obtained room temperature for $\mathrm{ZnFe}_{2} \mathrm{O}_{4}$ nanoparticles. The magnetic parameters such as magnetic saturation $\left(\mathrm{M}_{\mathrm{S}}\right)$, retenivity $\left(\mathrm{M}_{\mathrm{R}}\right)$ and coercivity $\left(\mathrm{H}_{\mathrm{C}}\right)$ of the $\mathrm{ZnFe}_{2} \mathrm{O}_{4}$ nanoparticles are found to be $18.6 \mathrm{emu} / \mathrm{g}, 725.5 \mathrm{G}$ and $8.1 \mathrm{emu} / \mathrm{g}$ respectively; it also indicates that $\mathrm{ZnFe}_{2} \mathrm{O}_{4}$ nanoparticles are ferromagnetic in nature.

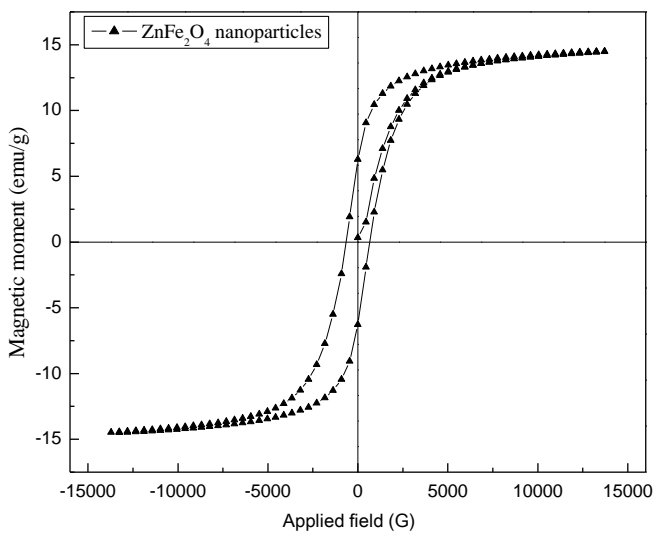

Fig. 5 Magnetization curve for $\mathrm{ZnFe}_{2} \mathrm{O}_{4}$ particles

\section{Conclusion}

Nanocrystalline $\mathrm{ZnFe}_{2} \mathrm{O}_{4}$ has been synthesized by combustion route. XRD analysis validated the structure of $\mathrm{ZnFe}_{2} \mathrm{O}_{4}$ nanoparticles with the crystallite size of $24-30 \mathrm{~nm}$ supported by the SEM images. The results of VSM indicate that the saturation magnetization of $\mathrm{ZnFe}_{2} \mathrm{O}_{4}$ shows a maximum value $18.6 \mathrm{emu} / \mathrm{g}$ at room temperature.

\section{References}

[1] Lou Kondic, Javier A. Diez, Philip D. Rack, Y. Guan, Jason D. Fowlkes, Nanoparticle assembly via the dewetting of patterned thin metal lines: Understanding the instability mechanisms, Phys. Rev. 79 (2009) 026302-1-7.

[2] A. Bhattacharyya, P.C. Chakraborty, S. Mukherjee, M.K. Mitra, G.C. Das Preparation of alumina-silica-nickel nanocomposite by in situ reduction through sol-gel route, Sci. Tech. Adv. Mater. 2 (2001) 449-454.

[3] K. Raj, B. Moskowitz, R. Casciari, Advances in ferrofluid technology, Jour. Magn. Magn. Mater. 149 (1995) 174-180.

[4] A.K. Gupta, M. Gupta, Synthesis and surface engineering of iron oxide nanoparticles for biomedical applications, Biomater. 26 (2005) 3995-4021.

[5] Philip D. Stevens, Jinda Fan, H.M.R. Gardimalla, Max Yen, Yong Gao, Superparamagnetic nanoparticle-supported catalysis of suzuki cross-coupling reactions, Org. Lett. 7 (2005) 2085-2088.

[6] L. Chen, Y. Shen, J. Bai, Large-scale synthesis of uniform spinel ferrite nanoparticles from hydrothermal decomposition of trinuclear heterometallic oxo-centered acetate clusters, Mater. Lett. 63 (2009) 1099-1101.

[7] J.S.Jang, P.H. Borse, J.S. Lee, O.S. Jung, C.R. Cho, E.D. Jeong, et al., Synthesis of nanocrystalline $\mathrm{ZnFe}_{2} \mathrm{O}_{4}$ by polymerized complex method for its visible light photocatalytic application: an efficient photo-oxidant, Bull. Korean. Chem. Soc. 30 (2009) 1738-1742.

[8] C.H. Chen, Y.H. Liang, W.D. Znang, $\mathrm{ZnFe}_{2} \mathrm{O}_{4} /$ MWCNTs composite with enhance photocatalytic activity under visible light irradiation, J. Alloy. Compds. 501 (2010) 168-172.

[9] Chao Liu, Bingsuo Zou, Adam J. Rondinone, Z. John Zhang, Reverse micelle synthesis and characterization of superparamagnetic $\mathrm{MnFe}_{2} \mathrm{O}_{4}$ spinel ferrite nanocrystallites, J. Phys. Chem. B 104 (2000) 1141-1145.

[10] G.C. Hadjipanayis, R.W. Siegel, Nanophase materials, Kluwer Academic Publishers, Netherlands, 1994.

[11] T. Pannaparayil, R. Marande, S. Komarneni, S.G. Sankar, A novel lowtemperature preparation of several ferromagnetic spinels and their magnetic and Mossbauer characterization, Jour. Appl. Phys. 64 (1988) 5641-5643.

[12] N. Ponpadian, A. Narayanasamy, C.N. Chinnasamy, N. Shivkumar, J.M. Greneche, et al., Neel temperature enhancement in nanostructured nickel zinc ferrite, Appl. Phys. Lett. 86 (2005) 192510-1-3.

[13] S. Zhou, K. Potzger, D. Burger, K. Kuepper, M. Helm, J. Fassbender, H. Schmidt Inverse spinel $\mathrm{ZnFe}_{2} \mathrm{O}_{4}$ nanoparticles synthesized by ion implantation and post-annealing: An investigation using X-ray spectroscopy and magnetotransport, Nuclear Instrum. Method Phys. Res. B: Beam Interactions with Materials and Atoms 267 (2009) 1620-1622.

[14] D. Sibera, U. Narkiewicz, N. Guskos, G. Zonierkiewicz, The preparation and EPR study of nanocrystalline $\mathrm{ZnFe}_{2} \mathrm{O}_{4}$, Jour. Phys.: Conference Series 146 (2009) 012014-1-5.

[15] Malick Jean, Virginie Nachbaur, Determination of milling parameters to obtain mechanosynthesized $\mathrm{ZnFe}_{2} \mathrm{O}_{4}$, Jour. Alloy. Compd. 454 (2008) 432-436.

[16] S. Bangale, S. Bamane, Synthesis, Characterization and hydrophilic properties of nanocrystalline $\mathrm{ZnFe}_{2} \mathrm{O}_{4}$ oxide, Res. J. Recent Sci. 1 (2012) 202-206. 
[17] N.M. Deraz, A. Aliarifi, Microstructure and magnetic studies of zinc ferrite nanoparticles, Int. J. Electrochem. Sci. 79 (2012) 6501-6511.

[18] H.K. Chen, C.Y. Yang, A study on the preparation of zinc ferrite, Scand. J. Metall. 30 (2001) 238-241.

[19] J.Y. Patil, D.Y. Nadargi, J.L. Gurav, I.S. Mulla, S.S. Suryavanshi, Synthesis of glycine combusted $\mathrm{NiFe}_{2} \mathrm{O}_{4}$ spinel ferrite: A highly versatile gas sensor, Mater. Lett. 124 (2014) 144-147.

[20] P.M. Prithviraj Swamy, S. Basavaraja, Arunkumar Lagashetty, N.V. Srinivas Rao, R. Nijagunappa, A. Venkataraman, Synthesis and characterization of zinc ferrite nanoparticles obtained by self-propagating low-temperature combustion method, Bull. Mater. Sci. 34 (2011) 1325-1330.
[21] Ajai Kumar S. Molakeri, S. Kalyane, Synthesis, characterization and DC conductivity of PANI/ZnFe $2 \mathrm{O}_{4}$ composites, Int. J. Innovat. Res. Sci. Eng. Technol. 4 (2015) 5728-5737.

[22] S. Chiu, S. Radiman, M.H. Abdullah, P.S. Khiew, N.M. Huang, R. Abd-Shukor, One pot synthesis of monodisperse $\mathrm{Fe}_{3} \mathrm{O}_{4}$ nanocrystals by pyrolysis reaction of organometallic compound, Mater. Chem. Phys. 106 (2007) 231-235.

[23] N.S. Ramgir, Y.K. Hwang, I.S. Mulla, J.S. Chang, Effect of particle size and strain in nanocrystalline $\mathrm{SnO}_{2}$ according to doping concentration of ruthenium, Solid State Sci. 8 (2006) 359-362. 